\title{
Toxicity of thiolated silica nanoparticles modified with sulfobetaine methacrylate for potential use in chemotherapy drug conjugation
}

\author{
Abdulmajeed G. Almutary ${ }^{1}$, Barbara J. S. Sanderson ${ }^{1}$, Zahra Alhalili ${ }^{2,}$ Amanda V. Ellis ${ }^{3}$ \\ ${ }^{1}$ School of Medicine, Nursing and Health Sciences, Flinders University, GPO Box 2100, Adelaide, South Australia 5001, Australia. \\ ${ }^{2}$ School of Chemical \& Physical Sciences,Flinders University, GPO Box 2100, Adelaide, South Australia 5001, Australia. \\ ${ }^{3}$ Department of Chemical and Biomolecular Engineering, University of Melbourne, Parkville, Victoria 3010, Australia.
}

\begin{tabular}{l} 
ARTICLE INFO \\
\hline Article history: \\
Received on: 09/05/2017 \\
Accepted on: 22/06/2017 \\
Available online: 30/07/2017 \\
\hline Key words: \\
Monodispersed silica; \\
zwitterionc SBMA; HaCaT; \\
Caco-2; MTT assay; LDH \\
assay; size distribution.
\end{tabular}

\begin{abstract}
Nanoparticles (NPs) are promising substrates for the delivery of chemotherapy drugs to solid tumours. However, after injection these foreign bodies are often eliminated by the reticulo endothelial system (RES) within seconds or minutes. Previous studies overcome this issue by coating nano-drug carriers with a surfactant which extended the circulatory half-life of NPs and prevented opsonization. In the current study, thiolated silica nanoparticles ( $\mathrm{SiO} 2)$ were synthesized using the Stöber method then coated with low fouling zwitterionc sulfobetaine methacrylate (SBMA) using thiol-ene addition. Scanning electron micrographs (SEM) revealed monodispersed spherical particles with dynamic light scattering (DLS) showing a small increase in nanoparticle average diameter after modification with SBMA. Toxicity of the SiO2-SBMA nanoparticles (concentrations between $0.05-2.00 \mathrm{mg} / \mathrm{mL}$ ) was investigated using 3-(4,5-dimethylthiazol-2-yl)-2,5-diphenyltetrazolium bromide (MTT), lactate dehydrogenase (LDH) and crystal violet assays on human colon carcinoma (Caco-2) and human skin keratinocytes (HaCaT) cell lines for 4, 24 and $48 \mathrm{~h}$. The particles were also exposed to ultraviolet light (UV) to determine any possible degradation with zeta potential measurements revealing strongly anionic particles after 1 h UV light exposure. The SiO2-SBMA nanoparticles did not decrease the mitochondrial activity of Caco-2 or $\mathrm{HaCaT}$ cell lines using MTT assays; however, the LDH leakage increased and relative cell number decreased at $2.00 \mathrm{mg} / \mathrm{mL}$ and was clearly observed after the particles were exposed to UV light. These results indicate that concentrations $\leq 1.50 \mathrm{mg} / \mathrm{mL}$ of $\mathrm{SiO} 2$-SBMA low toxicity are biocompatible and show potential as a chemotherapy drug conjugate.
\end{abstract}

\section{INTRODUCTION}

Chemotherapy is necessary for the treatment of most solid tumours; however, adverse side effects often limit its benefits and impact on the patients quality of life (Nowak et al., 2003; Sutradhar and Amin, 2014). Repeated cycles of chemotherapy can cause multidrug resistance (Peer and Margalit, 2006; Kuo et al., 2011). In order to address these issues there is a need to develop new methods of transporting medicines without causing damage to other tissues or organs (Farokhzad and Langer, 2009; Prausnitz et al., 2004; Jin and Ye, 2007). Nanoparticles (NPs) promote drug release, and drug

\footnotetext{
* Corresponding Author

E-mail: Almu0047 @ flinders.edu.au; Tel.: +61 432332385
}

accumulation, in tumours and can have more favourable pharmacokinetics than the free drug (Amoozgar and Yeo, 2012). NPs delivery to tumours depends on the physiological and anatomical features of the tumour and its environment (Amoozgar and Yeo, 2012). As the tumour spreads, higher demand for gas exchange, nutrients and waste removal lead to the formation of new blood vessels (Flier et al., 1995; Rak and Joanne, 2004). This happen by the extension of vasculature towards the tumour and the mobility of the progenitor endothelial cells (Narang and Mahato, 2006). Factors such as fibroblast growth and endothelial growth stimulate the extension of tumour vasculature (Gao et al., 2008; Folkman, 1971). However, antiangiogenic factors can cause incompatible expansion and defects in the architecture of tumour vasculature (Fukumura and Jain, 2007; Hanahan and Folkman, 1996). 
Studies using transplanted rodent tumours revealed that the pore size of tumours microvessels range between $100 \mathrm{~nm}$ to $780 \mathrm{~nm}$ in diameter, therefore; this is an important feature in the extravasation of NPs (Hobbs et al., 1998; Li and Huang, 2010). Additionally, tumours commonly have poor lymphatic drainage, which can reduce the removal of NPs (Maeda et al., 2000). This phenomenon is known as enhanced permeability and retention (EPR) (Canelas et al., 2009; Aliabadi et al., 2008; Matsumura and Maeda, 1986; Sutradhar and Amin, 2014). To realize the optimal benefits of the EPR effect, NPs must circulate for a long period, but the reticuloendothelial system (RES) which protects the body from extraneous particles, is a major obstacle to the retention of NPs (Hsu and Juliano, 1982, Senior, 1986). The clearance of foreign bodies such as NPs is initiated by phagocytic cells in the tissue and blood (Pratten and Lloyd, 1986; Bartneck et al., 2009) and mediated (labeling the surface of NPs as a foreign body) by the plasma proteins or complement fragment (Moghimi and Patel, 1998). Many studies have shown that if the NPs surface is not protected from opsonization it will be cleared from the blood within minutes by the RES (Semple et al., 1998; Moghimi and Szebeni, 2003; Mohanraj and Chen, 2006). Some of surface coatings can prevent nanoparticle opsonization and aggregation, improve cellular uptake, increase wettability, and affect degradation rates (Khung and Narducci, 2015). This include polySBMA (sulfobetaine methacrylate), PEG, dextran, chitosan, pullulan, sodium oleate, dodecylamine, polysorbate 80 , poloxamer 188, polyvinyl alcohol, poly-2- methyl-2-oxazoline, polyvinylpyrrolidone, and $\alpha$-tocopherol PEG-1000 succinate (Izquierdo-Barba et al., 2016; Liu et al., 2014).

The circulatory half-life of NPs is greatly affected by their shape, size, surface chemistry, surface area and multicomposition (Yamamoto et al., 2001, Longmire et al., 2011, Sheng et al., 2009, Pistone et al., 2016). Charged and hydrophobic NPs have shorter circulatory half-lives because of significant opsonization (Amoozgar and Yeo, 2012). The method of opsonization is one of the most important biological barriers to control the delivery of drugs into organs. Almost all NPs that are administrated systematically are coated with electrically neutral hydrophobic surface layers called a "stealth coating" which extends the half-life of NPs to $>40 \mathrm{~h}$ (Moghimi et al., 2001). Administration of NPs via intradermal or subcutaneous injection showed a different distribution depending on the absence or presence of coatings (Hirai et al., 2012; Liu et al., 2014). The degree of NPs coating plays an important factor in reaching targeted tissues(Liu et al., 2014). For instance, poly (ethylene) glycol (PEG)-coated NPs reaches the lymphatic vessels and their circulatory system faster than free injected NPs (Liu et al., 2014; Iannazzo et al., 2017).

Most of the surface stabilization of NPs is accomplished either with surfactant and/or with non-ionic hydrophilic polymers. Polyethylene glycol (PEG) is often applied, called PEGylation; however, it forms a flexible layer on the surface of the NPs that can hinder the adsorption of opsonins by steric hindrance and phagocytic effects (Heald et al., 2002; Moffatt and Cristiano,
2006; Huang et al., 2001; Amoozgar and Yeo, 2012; Gref et al., 2000). The impact of PEGylation on the extension of NP circulatory half-life is well recognized (Verrecchia et al., 1995). Verrechia et al (Verrecchia et al., 1995) identified that PEGylated NPs were more concentrated in the plasma and liver than nonPEGylated NPs. Significantly, the uptake of PEGylated polylactic acid (PLA) NPs by the liver was lower than that of non-PEGylated PLA NPs by $9 \%$ (Amoozgar and Yeo, 2012).

Although the PEG stealth coating method has shown successful protection for a variety of NPs, other studies have reported its disadvantages (Zhang et al., 2008; Gref et al., 1994; Suh et al., 2007; Poon et al., 2011). The delivery of the drug to the targeted cells often involves the uptake of the NPs, especially when the drug depends on the NPs to enter or exit from the cells. NPs pass through five stages (1) transport to the extracellular matrix, (2) bonding to the cell membrane by receptors, (3) internalization into the cells, (4) drug release and exit from intracellular vesicles to cytosol, and (5) transfer to the targeted organelles. Therefore, a method for coating surfaces to prevent protein adsorption is to use zwitterionic molecules (Khalil et al., 2006; Gupta et al., 2003; Du et al., 1997). Estephan et al. (2011) compared the efficacy of protein adsorption between PEGylated and zwitterion coated silica particles. PEGylation formed three dimensional coatings whereas the zwitterion formed monolayertype coverage with lower thicknesses(Estephan et al., 2011). The silica-modified NPs were challenged with serum, salt, lysozyme and albumin at 25 and $37{ }^{\circ} \mathrm{C}$. Both methods were effective at preventing protein adsorption and aggregation of particles. The mechanism for adsorption resistance was thought to be based on preventing ion pairing between protein and surface charges, which releases counterions and water molecules, an entropic driving force enough to overcome a disfavored enthalpy of adsorption.

There is an assumption that NPs can use a mechanism to pass through gastrointestinal barriers by (1) paracellular crossing of NPs through the intestinal epithelial cells as a result of their small size (<50 nm); (2) NPs uptake by intestinal enterocytes via endocytosis (size $<500 \mathrm{~nm}$ ) and (3) lymphatic absorption of the NPs by $M$ cells (size $<5 \mu \mathrm{m}$ ). Also coating NPs with the suitable bioadhesive material can rise their ability to fight multi-drug resistance proteins (Win and Feng, 2005). However, these nanoparticles may engulfed by macrophages in the liver which is the organ most likely influenced regardless of the method of preparation(Owens and Peppas, 2006). NPs can also accumulate in the lungs, the spleen, the bone marrow, the lymph nodes, the colon, and the brain causing sever toxicity(Garnett and Kallinteri, 2006, Hagens et al., 2007).

Silica nanoparticles are broadly used in biomedical applications as drug carriers and vehicles for gene delivery (Roy et al., 2005; Csőgör et al., 2003). In this study, we describe the synthesis of thiolated silica nanoparticles coated with a zwitterionic sulfobetaine methacrylate (SBMA) coating using a thiol-ene addition reaction. The toxicity of these nanoparticles to human colon carcinoma cell line (Caco-2) and human skin keratinocytes (HaCaT) was then determined using 3-(4,5- 
dimethylthiazol-2-yl)-2,5-diphenyltetrazolium bromide (MTT) and lactate dehydrogenase (LDH) assays.

\section{MATERIALS METHODS}

\section{Reagents and NPs}

All reagents were from Sigma Aldrich, Australia unless otherwise stated. These included, [3-(4,5-dimethylthiazol-2yl)diphenyltetrazolium bromide] MTT, $\beta$-nicotinamide adenine dinucleotide hydrate (NADH), $\beta$-nicotinamide adenine dinucleotide (NAD), phenazine methosulfate (PMS), Trizma base, Trizma $\mathrm{HCl}$, lithium lactate, iodonitrotetrazolium chloride (INT), Triton X-100, Tetraethyl orthosilicate (98\%) (TEOS), (3mercaptopropyl)trimethoxysilane (MPTMS) and [3(methacryloylamino)propyl] dimethyl(3- sulfopropyl) ammonium hydroxide inner salt (sulfobetaine methacrylate (SBMA)). The culture media used was Dulbecco's Modified Eagle Medium (DMEM) and Roswell Park Memorial Institute (RPMI) with 10\% heat-inactivated fetal bovine serum (FBS) (HYQ®, Hyclone, Utah, USA), penicillin and streptomycin. Millipore Milli-Q water with resistivity $=18.2 \mathrm{M} \Omega$.cm was used for all the experiments.

\section{Preparation of $\mathrm{SiO}_{2}$ Nanoparticles}

Silica nanoparticles and thiolated silica nanoparticles were synthesized by a modified Stöber method (Fig. 1) (Ibrahim et al., 2010). A silica precursor of TEOS (1 mL) was added rapidly to a mixture of $95 \%$ ethyl alcohol $(10 \mathrm{~mL})$ and Milli-Q water (3 $\mathrm{mL}$ ). The reaction was allowed to proceed for $30 \mathrm{~min}$ with mild stirring at $50{ }^{\circ} \mathrm{C}$ to obtain a homogeneous mixture. Subsequently, ammonia solution $(30 \%)(1 \mathrm{~mL})$ was injected drop-wise over an 8 min period with stirring. The mixture gradually changed from transparent to milky as the nanoparticles formed. The mixture was then stirred for a further $2 \mathrm{~h}$. The resultant precipitate was then centrifuged at $101890 \mathrm{G}$ and washed with Milli-Q water four times. Finally, the silica particles were dried overnight at $75^{\circ} \mathrm{C}$.

\section{Preparation of Thiolated $\mathrm{SiO}_{2}$ Nanoparticles}

A mixture of $(1 \mathrm{~mL})$ TEOS and $(0.25 \mathrm{~mL})$ MPTMS was stirred for $2 \mathrm{~min}$ then added to a mixture of ethyl alcohol $(10 \mathrm{~mL})$ and Milli-Q water $(3 \mathrm{~mL})$. The reaction mixture was stirred for 30 min at $50{ }^{\circ} \mathrm{C}$, and then ammonia solution $(30 \%)(1 \mathrm{~mL})$ was injected drop-wise over an $8 \mathrm{~min}$ period with stirring. The mixture was then stirred for a further $2 \mathrm{~h}$. The resulting gel was centrifuged at $101890 \mathrm{G}$ and washed with Milli-Q water four times before being dried overnight in an oven at $80{ }^{\circ} \mathrm{C}$. After drying, the gel became a white powder.

\section{Synthesis of Zwitterionic Sulfobetaine Methacrylate (SBMA) Coated Silica Nanoparticles by Thiol-ene addition}

SBMA (5 g) was dissolved in Milli-Q water (25 mL) and placed in a two neck round bottom flask under nitrogen $\left(\mathrm{N}_{2}\right)$ with stirring for $30 \mathrm{~min}$. The synthesized thiolated $\mathrm{SiO}_{2}$ nanoparticles $(1.32 \mathrm{~g})$ were then added to the solution and the temperature was increased gradually to $70{ }^{\circ} \mathrm{C}$. Subsequently, V50 initiator $(50 \mathrm{mg})$, dissolved in Milli-Q water $(2.5 \mathrm{~mL})$ was added, and the reaction mixture was stirred for approximately $17 \mathrm{~h}$ at $70{ }^{\circ} \mathrm{C}$. The resulting suspension was centrifuged at $101890 \mathrm{G}$ and washed four times with acetone. The resultant powder (called $\mathrm{SiO}_{2}$-SBMA NPs) was dried under $\mathrm{N}_{2}$ and protected from light by storing it in a brown sealed vial.

\section{STEP 1}

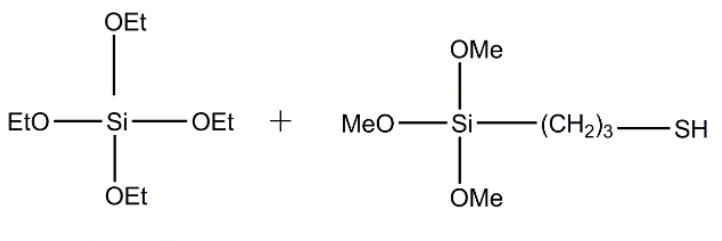

tetraethoxysilane

(TEOS) (3-mercaptopropyl)trimethoxysilane (MPTMS)

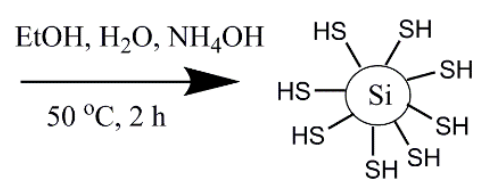

thiol functionalized $\mathrm{SiO}_{2} \mathrm{NPs}$

\section{STEP 2}

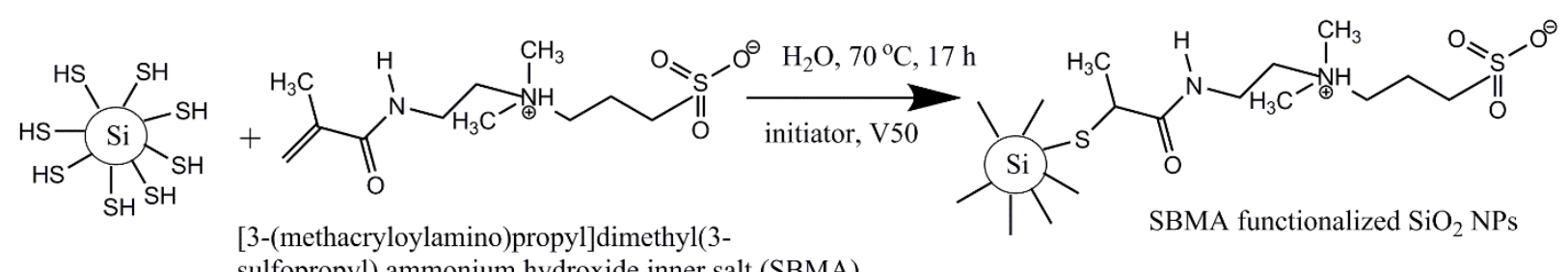

sulfopropyl) ammonium hydroxide inner salt (SBMA)

Fig. 1: Synthesis of thiolated silica nanoparticles and subsequent thiol-ene reaction to produce $\mathrm{SiO}_{2}-\mathrm{SBMA}$ nanoparticles. 


\section{Nanoparticle Characterization}

Scanning electron microscopy (SEM) was performed on the thiolated and SiO2-SBMA NPs. The samples were sputter coated with a $10 \mathrm{~nm}$ layer of platinum using a Quorumtech K757X Sputter coater. The images of the sample were collected using a CAMS can MX2500 SEM with a field emission source at an accelerating voltage of $10 \mathrm{kV}$. The hydrodynamic diameter (determined in RPMI medium) and the zeta-potential were measured by dynamic light scattering (DLS)using Malvern HPPS. Data was acquired with a scattering angle close to $180^{\circ}$ at a temperature of $25^{\circ} \mathrm{C}$.

\section{Cell Culture}

Caco-2 and $\mathrm{HaCaT}$ were obtained from the American Type Culture Collection (ATCC). Caco-2 cells were grown in DMEM and HaCaT in RPMI at pH 7.4, with $10 \%$ FBS, and a $1 \%$ antibiotic mixture of penicillin $(10,000$ units $/ \mathrm{mL})$ and streptomycin $(10,000 \mu \mathrm{g} / \mathrm{mL})$. The cells were maintained in a T-75 flask at $1 \times 10^{6}$ cells $/ \mathrm{mL}$. When the cells reached $80 \%$ confluence they were trypsinized and sub-cultured (Sambuy et al., 2005). The cells were maintained in a humidified incubator with $5 \% \mathrm{CO}_{2}$ at $37{ }^{\circ} \mathrm{C}$. The cell density after trypsinization was determined by Trypan blue counting (Sambuy et al., 2005).

\section{Cell Exposure to Nanoparticles}

$\mathrm{SiO}_{2}$-SBMA NPs were diluted in deionized water (stock at $20 \mathrm{mg} / \mathrm{mL}$ ), then mixed by vortexing for $5 \mathrm{~min}$, followed by dilution to the required concentration with media. Caco-2 and $\mathrm{HaCaT}$ cells were seeded at 10,000 cells/well in a 96 well flat bottom microplates, then incubated overnight to allow adherence. Cells were exposed to $\mathrm{SiO}_{2}$-SBMA NPs at six concentrations $(0.05,0.1,0.5,1.0,1.5,2.0 \mathrm{mg} / \mathrm{mL})$ and the control was Triton X100 for 4, 24 and $48 \mathrm{~h}$. After exposure, the solution was removed, and the cells were washed twice with phosphate buffered saline (PBS) at $\mathrm{pH} 7.4$ to remove any excess NPs.

\section{UV-light exposure of $\mathrm{SiO}_{2}$-SBMA NPs}

$\mathrm{SiO}_{2}$-SBMA NPs were exposed to UV light at $365 \mathrm{~nm}$ with a peak irradiance of $13.05 \mathrm{~mW} / \mathrm{cm}^{2}$ for $1 \mathrm{~h}$.

\section{MTT Assay}

A MTT assay was used as an indicator of metabolic viability where Yellow MTT is enzymatically changed to insoluble purple formazan for visualization. Each concentration was examined in four technical replicates and the experiment was repeated three times $(n=3)$. Media containing MTT tetrazolium salt $(5 \mathrm{mg} / \mathrm{mL}$ ) was added to exposed cells for $4 \mathrm{~h}$. The purple formazan formed inside the cells was dissolved with $10 \%$ sodium dodecyl sulphate (SDS) in $0.1 \mathrm{M} \mathrm{HCl}$. Absorbance was read using a spectrophotometer at a primary wavelength of $570 \mathrm{~nm}$ and a reference wavelength of $630 \mathrm{~nm}$. 3.10. LDH Assay Caco-2 and $\mathrm{HaCaT}$ cells were seeded in triplicate wells at $1 \times 10^{4}$ viable cells $/ 100 \mu \mathrm{L}$ DMEM in 96 flat bottom plates. The cells were cultured for $16 \mathrm{~h}$ to allow adherence then media was replaced with six different concentrations of nanoparticles, plus controls, for 4 , 24 and $48 \mathrm{~h}$. After exposure, the 96 flat bottom plate was spun at $1200 \mathrm{rpm}$ and $50 \mu \mathrm{L}$ aliquots of cell lysate from each well and concentration were transferred to a new 96 flat bottom plate containing $150 \mu \mathrm{L}$ of LDH stain per well. Cells were incubated at room temperature for $5 \mathrm{~min}$ then the absorbance was read at 590 $\mathrm{nm}$ using a spectrophotometer.

\section{Crystal Violet Assay (screening for cell adherence phenotype)}

After $\mathrm{HaCaT}$ cells exposed to $\mathrm{SiO}_{2} \mathrm{SBMA}$, the plates were washed with PBS and $50 \mu 1$ of crystal violet stain was added and incubated at room temperature for 15 minutes. The Stain was washed off with demineralized water and the plates were left to dry overnight. A 33\% (v/v) acetic acid solution was then added and the optical density (OD) at $570 \mathrm{~nm}$ was read within minutes using ELISA reader. Six technical replicate wells per treatment and three biological replicates were carried out for each treatment experiment. The results were expressed as percentage viability compared to untreated control.

\section{Statistical Analysis}

The data were expressed as means +/- the standard deviation (SD) of at least three independent experiments using one-way analysis of variance (ANOVA) and Tukey-Kramer multiple comparisons test using SPSS software to compare exposure groups. All comparisons were considered significant at levels $p<0.05$.

\section{RESULTS AND DISCUSSION}

The formation of thiolated silica particles is depicted in Fig. 1, Step 1\&2. During hydrolysis reactions, an intermediate compound $\left[\mathrm{Si}\left(\mathrm{OC}_{2} \mathrm{H}_{5}\right)_{4 \times}(\mathrm{OH}) \mathrm{X}\right]$ containing silanol groups is formed by nucleophilic substitution reactions between water molecules and ethoxy groups of TEOS. These silanol groups then undergo condensation reactions to form siloxane bridges, resulting in silica nanoparticles. However, when MPTMS is present the silanol groups can also undergo condensation reactions with the methoxy groups of the MPTMS. In this manner, silica nanoparticles containing both siloxane bridges and thiol functionalization can be achieved (Fig. 1, Step 1). Step 2 shows the synthetic pathway for the formation of SBMA functionalized $\mathrm{SiO}_{2}$ NPS. This relies on a thiol-ene addition reaction between the thiol modified $\mathrm{SiO}_{2} \mathrm{NPs}$ and the alkene moiety on the SBMA. The reaction typically results in an anti-Markovnikov addition to the alkene. The reaction is stereo-selective and occurs rapidly with high yields (Yang and Rioux, 2014). Fig. 2 a\&b shows the size distribution of the particles both before and after the reaction of the thiolated $\mathrm{SiO}_{2}$ NPs with SBMA measured using DLS. SBMA functionalization is shown as an increase in the average size of the particles of approximately $8 \mathrm{~nm}$, increasing from $87 \mathrm{~nm}$ to $95 \mathrm{~nm}$ after functionalization. This increase in hydrodynamic radius is larger than the length scale of the attached moiety but is a result of the shielding attraction between the zwitterions thus giving rise to an increase in the hydrodynamic volume. 


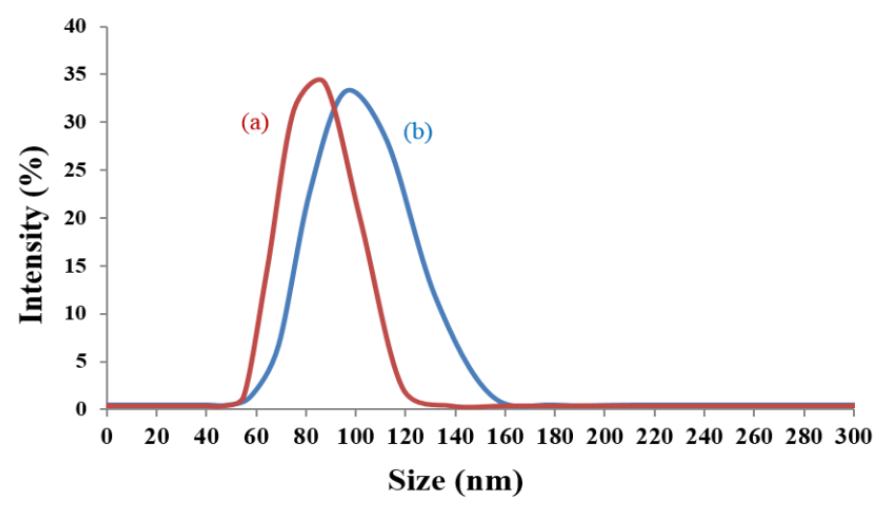

Fig. 2. Analysis of nanoparticles using DLS. (a) $\mathrm{SiO}_{2}$ nanoparticles (average size $=87 \mathrm{~nm})$ and $(b)$ after coating with SBMA (average size $=95 \mathrm{~nm})$.

SEM images of the thiolated and subsequently SBMA modified $\mathrm{SiO}_{2}$ NPS are shown in Fig. 3 a $\&$ b, respectively. The images show that both before and after SBMA modification the particles are monodisperse and spherical, indicating the thiol-ene addition has not damaged the NPs. Average dry particle size is $\leq$ $20 \mathrm{~nm}$.

Caco-2 and HaCaT cell viability studies were then carried out on the $\mathrm{SiO}_{2}$-SBMA NPs (concentrations between 0.05$2.00 \mathrm{mg} / \mathrm{mL}$ ) using a MTT assay. At all concentrations, the relative viability of the cells did not decrease (Fig. 4, left). However, photodegraded $\mathrm{SiO}_{2}$-SBMA due to exposure to UV light significantly decreased the cell viability of both Caco-2 and $\mathrm{HaCaT}$ on concentrations between $0.10-2.00 \mathrm{mg} / \mathrm{mL}$ (Fig. 4, right). The UV light exposed NPs $(1.5 \mathrm{mg} / \mathrm{mL})$, when exposed to Caco- 2 cells for $4 \mathrm{~h}$, showed an approximately $30 \%$ decrease in cell viability compared to the control. This was also observed with $\mathrm{HaCaT}$ cells at $48 \mathrm{~h}$. The toxicity of both cell lines is most likely due to the strongly anionic NPs after irradiation by UV light.

Fig. 5 shows the $\mathrm{LDH}$ assays which revealed that the highest concentration of $\mathrm{SiO}_{2}$-SBMA NPs $(2.00 \mathrm{mg} / \mathrm{mL})$ significantly increased the LDH leakage by nearly $25 \%$ at all time exposures. This was not seen by MTT assay which might be related to the particle interference with the MTT formazan.
These results indicate that both LDH release and MTT reduction accurately determine the toxic effect of $\mathrm{SiO}_{2}-\mathrm{SBMA}_{\text {. }}$ However, the MTT assay does not always correctly quantify NPs toxicity; this likely reflects differences in the point of the death pathway (Smith et al., 2011). The assessment of NPs cytotoxicity depends on the choice of the test system. Due to NPs optical activity and absorption values, they can influence the classical cytotoxicity assay. In our previous publication, $\mathrm{SiO}_{2} \mathrm{NPs}(20 \mathrm{~nm}$ in diameter) did not alter the MTT standard curve with or without the presence of HaCaT cells (Almutary and Sanderson, 2016). Cell death detected by crystal violet assay increased $20 \%$ at $2 \mathrm{mg} / \mathrm{ml}$ for 4 and $24 \mathrm{~h}$ exposure to $\mathrm{SiO}_{2}$-SBMA.Fig.6.LDH leakage was substantially increased by nearly $90 \%$ after UV light exposure. Yin et al (Yin et al., 2012) reported the cytotoxicity of four UV light exposed $(15 \mathrm{~mW}) \mathrm{TiO}_{2}$ NPs with size ranges between $25 \mathrm{~nm}$ and $325 \mathrm{~nm}$ and with two different crystal forms on HaCaT cell lines. Upon UV irradiation, all $\mathrm{TiO}_{2}$ NPs induced photocytotoxicity, and cell membrane damage, in a dose dependent manner. In the current study, photodegradation of $\mathrm{SiO}_{2}-\mathrm{SBMA}$ after $1 \mathrm{~h}$ exposure to UV light caused LDH leakage of Caco-2 cells. Therefore, it is assumed given previous literature that similar effects would be observed for the HaCaT cells (results not shown). NPs with zeta potentials in the range of -10 to $+10 \mathrm{mV}$ are neutral and between -30 and $+30 \mathrm{mV}$ are anionic and cationic (Clogston and Patri, 2011). The characteristics of NPs such as size, surface charge and agglomeration are crucial parameters in the determination of particle toxicity (Jiang et al., 2009). Cationic surfactants are used to protect NPs size, agglomeration and photopysical properties of particles. In this study, the zeta potential measurements of $\mathrm{SiO}_{2}$-SBMA were $-30 \mathrm{mV}$ prior to and $-70 \mathrm{mV}$ after UV light exposure. This shows an increase in anionic particle activity. Some cationic particles are moderately toxic, whereas anionic particles are often nontoxic (Janát-Amsbury et al., 2011). Therefore, it may be expected that the $\mathrm{SiO}_{2}$-SBMA NPs are rendered less toxic after UV treatment.
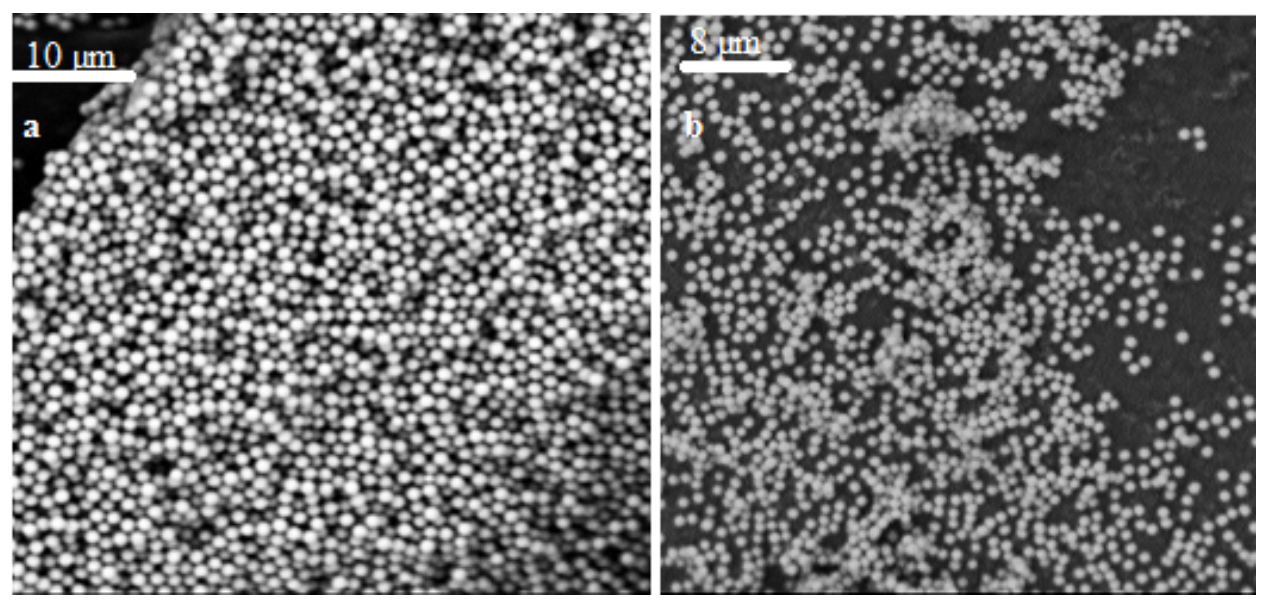

Fig. 3: SEM images of (a) monodisperse spherical thiolated $\mathrm{SiO}_{2}$ and (b) $\mathrm{SiO}_{2}-\mathrm{SBMA} \mathrm{NPs}$. The final NPs formed were spherical and uniform. 
$\mathrm{SiO}_{2}$-SBMA (Caco-2)

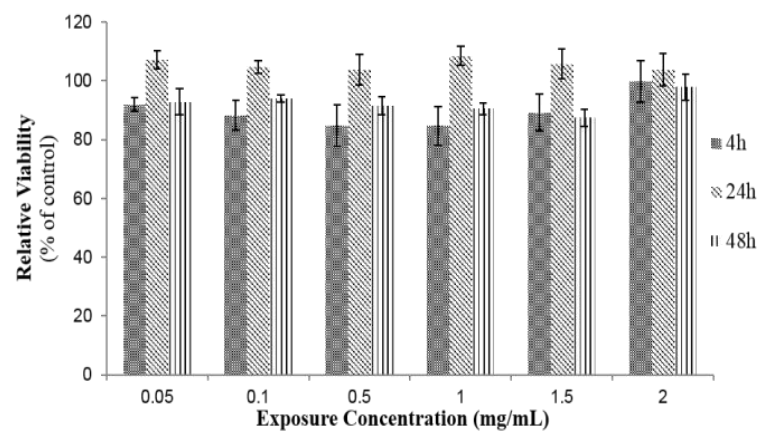

$\mathrm{SiO}_{2}$-SBMA (HaCaT)

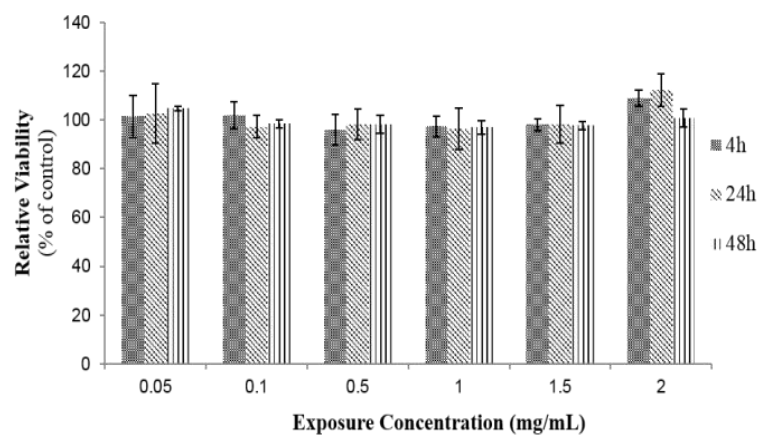

$\mathrm{SiO}_{2}$-SBMA UV (Caco-2)

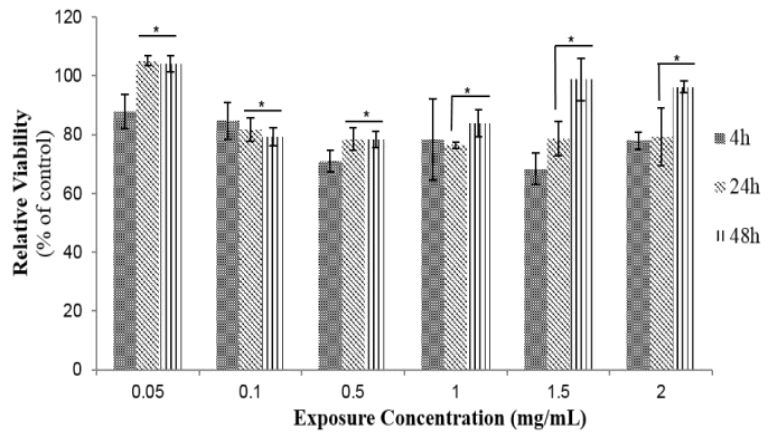

$\mathrm{SiO}_{2}$-SBMA UV (HaCaT)

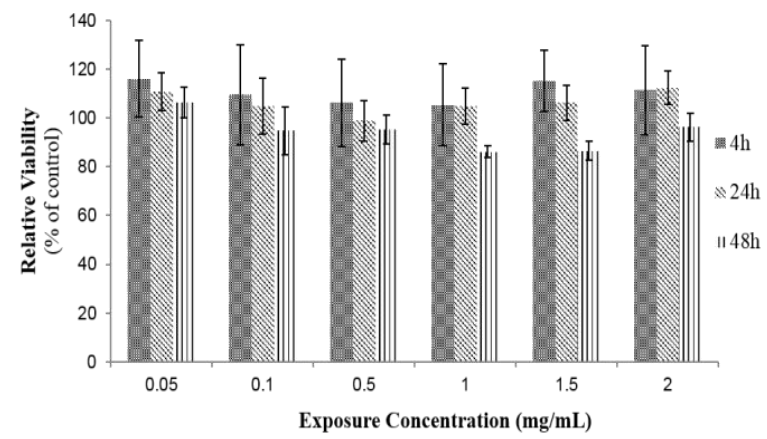

Fig. 4: Effect of $\mathrm{SiO}_{2}$-SBMA (left) and UV exposed NPs (right) on Caco-2 and HaCaT cell viability using a MTT assay. Caco-2 and HaCaT cells were exposed to different concentrations of $\mathrm{SiO}_{2}$-SBMA. Data are expressed as means \pm S.D. from three independent experiments. $* \mathrm{p}<0.05$ compared with control group.
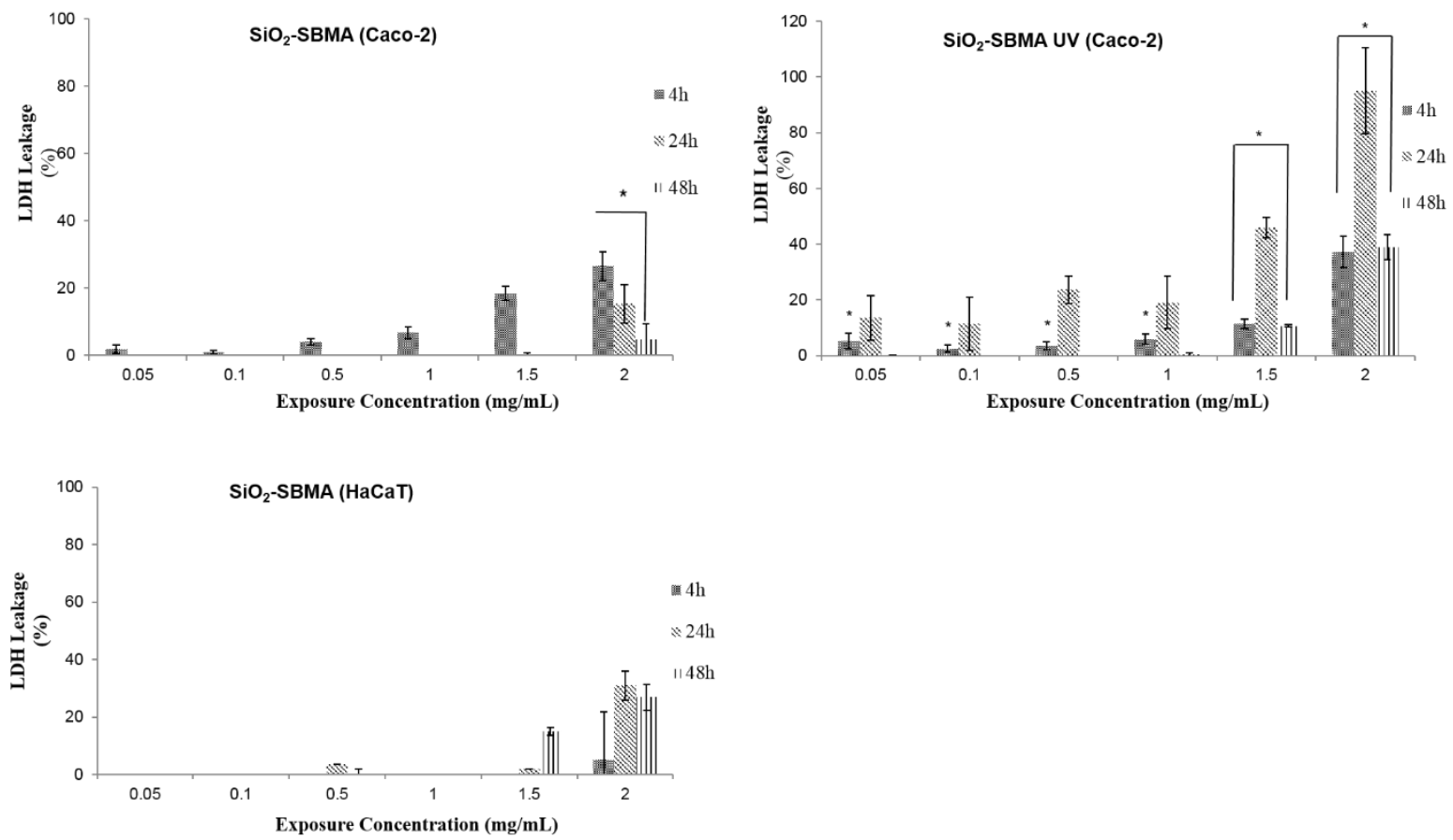

Fig. 5: Effect of $\mathrm{SiO}_{2}$-SBMA (left) and UV exposed NPs (right) on LDH leakage levels. Caco-2 and HaCaT cells were exposed to different concentrations of $\mathrm{SiO}_{2}$-SBMA. LDH levels increased at $2.00 \mathrm{mg} / \mathrm{mL}$ after 4, 24 and $48 \mathrm{~h}$ exposure. Data are expressed as means \pm S.D. from three independent experiments. $* p<0.05$ compared with control group. 


\section{SiO2-SBMA(HaCaT)}

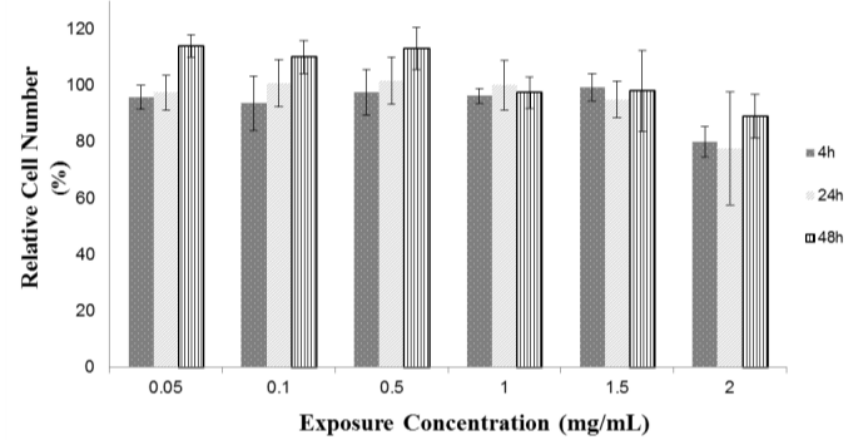

Fig. 6: Effect of $\mathrm{SiO}_{2}-\mathrm{SBMA}$ exposed NPs on relative cell number. $\mathrm{HaCaT}$ cell death increased at $2.00 \mathrm{mg} / \mathrm{mL}$. Data are expressed as means \pm S.D. from three independent experiments. ${ }^{*} p<0.05$ compared with control group.

Napierska et al (Napierska et al., 2009) reported the effect of monodisperse spherical $\mathrm{SiO}_{2} \mathrm{NPs}$ of different sizes on the growth of endothelial cells (EAHY926) cell line. The cytotoxic damage indicated by LDH release and the decrease of cell survival determined by the MTT assays was varied based on the $\mathrm{SiO}_{2}$ diameter. Concentrations led to a $50 \%$ decrease in cell viability for the smallest sized $\mathrm{SiO}_{2}$ (14-60 nm diameter) compared to a less cytotoxicity from the largest sized $\mathrm{SiO}_{2} \mathrm{NPs}(104 \mathrm{~nm}$ and $335 \mathrm{~nm})$. In addition, the smaller size $\mathrm{SiO}_{2}$ was shown to affect the exposed cells and cause cell death faster than the larger particles within just a few hours (Napierska et al., 2009).

Here, the $\mathrm{SiO}_{2} \mathrm{NP}$ concentrations were carefully chosen from our previous work on silica toxicity in which it was shown that when $\mathrm{SiO}_{2} \mathrm{NP}$ concentrations between $0.05-10 \mathrm{mg} / \mathrm{mL}$ were exposed to $\mathrm{HaCaT}$ cell lines there was a dose dependent increase in cell killing with increasing concentration when screened with a MTT assay (Almutary and Sanderson, 2016). In this work at $\mathrm{SiO}_{2}$ concentrations $\geq 2 \mathrm{mg} / \mathrm{mL}(24 \mathrm{~h})$ there was a decreased relative survival when assayed using MTT and the relative cell number was shown to decrease when assayed using a crystal violet assay. At $48 \mathrm{~h}$ treatment, cytotoxicity was observed at every treatment concentration. Moreover, the level of cytotoxicity was also time dependent $(4,24,48 \mathrm{~h})$ at every concentration.

\section{CONCLUSION}

In summary, thiolated $\mathrm{SiO}_{2}$ nanoparticles produced via a modified Stöber process were coated with a novel biocompatible zwitterionic sulfobetaine methacrylate via thiol-ene addition. The SEM images of both the thiol and SBMA modified $\mathrm{SiO}_{2}$ NPs showed spherical and monodispersed particles. DLS showed that there was an increase in NP size after modification with SBMA arising from an increase in hydrodynamic radius caused by a shielding interaction of the zwitterions. The toxicity of $\mathrm{SiO}_{2-}$ SBMA NPs was detected by MTT, LDH and crystal violet assays over 4,24 and $48 \mathrm{~h}$. The particle did not affect mitochondrial activity, even after $48 \mathrm{~h}$ exposure. Proliferation assays such as
MTT has two main limitations: one they can give false positive results in which a specific aspects of cellular metabolism are affected also they are unable to differentiate cell cycle inhibition and cellular death. The activated LDH enzyme and the decrease of relative cell number were found at $2.00 \mathrm{mg} / \mathrm{mL}$, predominately after 4 and $24 \mathrm{~h}$ exposure. The $\mathrm{SiO}_{2}$-SBMA zeta potential measurements were $-30 \mathrm{mV}$ before and $-70 \mathrm{mV}$ after UV light exposure. $\mathrm{TheSiO}_{2}$-SBMA NPs were exposed to UV light irradiation at $365 \mathrm{~nm}$ wavelength for $1 \mathrm{~h}$. A significant increase in LDH leakage of the Caco-2 cell line was detected. The photodegradation of the strongly anionic NPs caused by UV light could be avoided by reducing the exposure time to less than $1 \mathrm{~h}$ at the same wavelength. Further investigation is needed on the drug release and $\mathrm{SiO}_{2}$-SBMA cellular uptake.

\section{ACKNOWLEDGMENTS}

Authors would like to thank the Ministry of Higher Education, Saudi Arabia, for partial support of this project and the Australian Research Council Future Fellowship Funds.

\section{AUTHOR CONTRIBUTIONS}

AGA and AVE are equal contributors. AGA carried out the experiment work, contributed to acquisition, analysis, or interpretation of data, drafted the manuscript, and critically revised the manuscript for important intellectual content.AVE and BJSS contributed to conception and design, acquisition, drafted the manuscript, and critically revised the manuscript. Alhalili $\mathrm{Z}$ prepared the nanoparticles and partly revised the manuscript.

Conflict of interest: The authors declare that they have no conflict of interests.

\section{REFERENCE}

Aliabadi, H. M., Shahin, M., Brocks, D. R. \& Lavasanifar, A.Disposition of Drugs in Block Copolymer Micelle Delivery Systems Clinical pharmacokinetics, 2008; 47, 619-634.

Almutary, A. \& Sanderson, B.The MTT and Crystal Violet Assays Potential Confounders in Nanoparticle Toxicity Testing. International journal of toxicology,2016, 1091581816648906.

Amoozgar, Z. \& Yeo, Y.Recent advances in stealth coating of nanoparticle drug delivery systems. Wiley Interdisciplinary Reviews: Nanomedicine and Nanobiotechnology, 2012; 4, 219-233.

Bartneck, M., Keul, H. A., Zwadlo-Klarwasser, G. \& Groll, J.Phagocytosis independent extracellular nanoparticle clearance by human immune cells. Nano letters, 2009; 10, 59-63.

Canelas, D. A., Herlihy, K. P. \& Desimone, J. M.Top-down particle fabrication: control of size and shape for diagnostic imaging and drug delivery. Wiley Interdisciplinary Reviews: Nanomedicine and Nanobiotechnology, 2009; 1, 391-404.

Clogston, J. D. \& Patri, A. K.Zeta potential measurement. Characterization of nanoparticles intended for drug delivery, 2011, 63-70.

Csőgör, Z., Nacken, M., Sameti, M., Lehr, C.-M. \& Schmidt, H.Modified silica particles for gene delivery. Materials Science and Engineering: C,2003; 23, 93-97.

Du, H., Chandaroy, P. \& Hui, S. W.Grafted poly-(ethylene glycol) on lipid surfaces inhibits protein adsorption and cell adhesion. 
Biochimica et Biophysica Acta (BBA)-Biomembranes, 1997; 1326, 236248.

Estephan, Z. G., Schlenoff, P. S. \& Schlenoff, J. B.Zwitteration as an alternative to PEGylation. Langmuir, 2011; 27, 6794-6800.

Farokhzad, O. C. \& Langer, R.Impact of nanotechnology on drug delivery. ACS nano, 2009; 3, 16-20.

Flier, J. S., Underhill, L. H. \& Folkman, J.Clinical applications of research on angiogenesis. New England Journal of Medicine, 1995; 333 , $1757-1763$.

Folkman, J.Tumor angiogenesis: therapeutic implications. New England Journal of Medicine, 1971, 1182-6.

Fukumura, D. \& Jain, R. K.Tumor microvasculature and microenvironment: targets for anti-angiogenesis and normalization. Microvascular research, 2007; 74, 72-84.

Gao, D., Nolan, D. J., Mellick, A. S., Bambino, K., Mcdonnell, K. \& Mittal, V.Endothelial progenitor cells control the angiogenic switch in mouse lung metastasis. Science, 2008; 319, 195-198.

Garnett, M. C. \& Kallinteri, P.Nanomedicines and nanotoxicology: some physiological principles. Occupational Medicine, 2006; 56, 307-311.

Gref, R., Lück, M., Quellec, P., Marchand, M., Dellacherie, E., Harnisch, S., Blunk, T. \& Müller, R. 'Stealth'corona-core nanoparticles surface modified by polyethylene glycol (PEG): influences of the corona (PEG chain length and surface density) and of the core composition on phagocytic uptake and plasma protein adsorption. Colloids and Surfaces B: Biointerfaces, 2000; 18, 301-313.

Gref, R., Minamitake, Y., Peracchia, M. T., Trubetskoy, V., Torchilin, V. \& Langer, R.Biodegradable long-circulating polymeric nanospheres. Science, 1994; 263, 1600-1603.

Gupta, A. K., Berry, C., Gupta, M. \& Curtis, A.Receptormediated targeting of magnetic nanoparticles using insulin as a surface ligand to prevent endocytosis. NanoBioscience, IEEE Transactions on, $2003 ; 2,255-261$.

Hagens, W. I., Oomen, A. G., De Jong, W. H., Cassee, F. R. \& Sips, A. J.What do we (need to) know about the kinetic properties of nanoparticles in the body? Regulatory toxicology and pharmacology,2007; $49,217-229$

Hanahan, D. \& Folkman, J.Patterns and emerging mechanisms of the angiogenic switch during tumorigenesis. cell, 1996; 86, 353-364.

Heald, C., Stolnik, S., Kujawinski, K., De Matteis, C., Garnett, M., Illum, L., Davis, S., Purkiss, S., Barlow, R. \& Gellert, P.Poly (lactic acid)-poly (ethylene oxide)(PLA-PEG) nanoparticles: NMR studies of the central solidlike PLA core and the liquid PEG corona. Langmuir,2002; 18, 3669-3675

Hirai, T., Yoshikawa, T., Nabeshi, H., Yoshida, T., Tochigi, S., Ichihashi, K.-I., Uji, M., Akase, T., Nagano, K. \& Abe, Y.Amorphous silica nanoparticles size-dependently aggravate atopic dermatitis-like skin lesions following an intradermal injection. Particle and fibre toxicology,2012; 9, 3 .

Hobbs, S. K., Monsky, W. L., Yuan, F., Roberts, W. G., Griffith, L., Torchilin, V. P. \& Jain, R. K.Regulation of transport pathways in tumor vessels: role of tumor type and microenvironment. Proceedings of the National Academy of Sciences, 1998; 95, 4607-4612.

Hsu, M. \& Juliano, R.Interactions of liposomes with the reticuloendothelial system: II. Nonspecific and receptor-mediated uptake of liposomes by mouse peritoneal macrophages. Biochimica et Biophysica Acta (BBA)-Molecular Cell Research, 1982; 720, 411-419.

Huang, N.-P., Michel, R., Voros, J., Textor, M., Hofer, R., Rossi, A., Elbert, D. L., Hubbell, J. A. \& Spencer, N. D.Poly (L-lysine)-gpoly (ethylene glycol) layers on metal oxide surfaces: surface-analytical characterization and resistance to serum and fibrinogen adsorption. Langmuir, 2001; 17, 489-498.

Iannazzo, D., Pistone, A., Salamò, M., Galvagno, S., Romeo, R., Giofré, S. V., Branca, C., Visalli, G. \& Di Pietro, A.Graphene quantum dots for cancer targeted drug delivery. International Journal of Pharmaceutics, 2017; 518, 185-192.

Ibrahim, I. A., Zikry, A. \& Sharaf, M. A.Preparation of spherical silica nanoparticles: Stober silica. J. Am. Sci,2010; 6, 985-989.
Izquierdo-Barba, I., Colilla, M. \& Vallet-Regí, M.Zwitterionic ceramics for biomedical applications. Acta biomaterialia,2016; 40, 201211.

Janát-Amsbury, M., Ray, A., Peterson, C. \& Ghandehari, H.Geometry and surface characteristics of gold nanoparticles influence their biodistribution and uptake by macrophages. European Journal of Pharmaceutics and Biopharmaceutics, 2011; 77, 417-423.

Jiang, J., Oberdörster, G. \& Biswas, P.Characterization of size, surface charge, and agglomeration state of nanoparticle dispersions for toxicological studies. Journal of Nanoparticle Research,2009; 11, 77-89.

Jin, S. \& Ye, K.Nanoparticle-Mediated Drug Delivery and Gene Therapy. Biotechnology progress, 2007; 23, 32-41.

Khalil, I. A., Kogure, K., Akita, H. \& Harashima, H.Uptake pathways and subsequent intracellular trafficking in nonviral gene delivery. Pharmacological reviews, 2006; 58, 32-45.

Khung, Y. L. \& Narducci, D.Surface modification strategies on mesoporous silica nanoparticles for anti-biofouling zwitterionic film grafting. Advances in colloid and interface science, 2015; 226, 166-186.

Kuo, T.-C., Lu, H.-P. \& Chao, C. C.-K.The tyrosine kinase inhibitor sorafenib sensitizes hepatocellular carcinoma cells to taxol by suppressing the HURP protein. Biochemical pharmacology, 2011; 82, 184194.

Li, S.-D. \& Huang, L.Stealth nanoparticles: high density but sheddable PEG is a key for tumor targeting. Journal of controlled release: official journal of the Controlled Release Society, 2010; 145, 178.

Liu, L., Li, W. \& Liu, Q.Recent development of antifouling polymers: structure, evaluation, and biomedical applications in nano/micro-structures. Wiley Interdisciplinary Reviews: Nanomedicine and Nanobiotechnology,2014; 6, 599-614

Longmire, M. R., Ogawa, M., Choyke, P. L. \& Kobayashi, H.Biologically optimized nanosized molecules and particles: more than just size. Bioconjugate chemistry, 2011; 22, 993-1000.

Maeda, H., Wu, J., Sawa, T., Matsumura, Y. \& Hori, K.Tumor vascular permeability and the EPR effect in macromolecular therapeutics: a review. Journal of controlled release, 2000; 65, 271-284.

Matsumura, Y. \& Maeda, H.A new concept for macromolecular therapeutics in cancer chemotherapy: mechanism of tumoritropic accumulation of proteins and the antitumor agent smancs. Cancer research, 1986; 46, 6387-6392.

Moffatt, S. \& Cristiano, R. J.Uptake characteristics of NGRcoupled stealth PEI/pDNA nanoparticles loaded with PLGA-PEG-PLGA tri-block copolymer for targeted delivery to human monocyte-derived dendritic cells. International Journal of Pharmaceutics, 2006; 321, 143-154.

Moghimi, S. \& Patel, H.Serum-mediated recognition of liposomes by phagocytic cells of the reticuloendothelial system-the concept of tissue specificity. Advanced drug delivery reviews, 1998; 32, $45-60$.

Moghimi, S. M., Hunter, A. C. \& Murray, J. C.Long-circulating and target-specific nanoparticles: theory to practice. Pharmacological reviews, 2001; 53, 283-318.

Moghimi, S. M. \& Szebeni, J.Stealth liposomes and long circulating nanoparticles: critical issues in pharmacokinetics, opsonization and protein-binding properties. Progress in lipid research,2003; 42, 463478.

Mohanraj, V. \& Chen, Y.Nanoparticles-a review. Trop J Pharm Res, 2006; 5, 561-573

Napierska, D., Thomassen, L. C., Rabolli, V., Lison, D., Gonzalez, L., Kirsch-Volders, M., Martens, J. A. \& Hoet, P. H.Size-Dependent Cytotoxicity of Monodisperse Silica Nanoparticles in Human Endothelial Cells. Small,2009; 5, 846-853.

Narang, A. S. \& Mahato, R. I.Biological and biomaterial approaches for improved islet transplantation. Pharmacological reviews, 2006; 58, 194-243.

Nowak, A. K., Robinson, B. W. \& Lake, R. A.Synergy between chemotherapy and immunotherapy in the treatment of established murine solid tumors. Cancer research, 2003; 63, 4490-4496.

Owens, D. E. \& Peppas, N. A.Opsonization, biodistribution, and pharmacokinetics of polymeric nanoparticles. International journal of pharmaceutics, 2006; 307, 93-102. 
Peer, D. \& Margalit, R.Fluoxetine and reversal of multidrug resistance. Cancer letters, 2006; 237, 180-187.

Pistone, A., Iannazzo, D., Ansari, S., Milone, C., Salamò, M., Galvagno, S., Cirmi, S. \& Navarra, M.Tunable doxorubicin release from polymer-gated multiwalled carbon nanotubes. International Journal of Pharmaceutics, 2016; 515, 30-36.

Poon, Z., Chang, D., Zhao, X. \& Hammond, P. T.Layer-bylayer nanoparticles with a $\mathrm{pH}$-sheddable layer for in vivo targeting of tumor hypoxia. ACS nano, 2011; 5, 4284-4292.

Pratten, M. K. \& Lloyd, J. B.Pinocytosis and phagocytosis: the effect of size of a particulate substrate on its mode of capture by rat peritoneal macrophages cultured in vitro. Biochimica et Biophysica Acta (BBA)-General Subjects, 1986; 881, 307-313.

Prausnitz, M. R., Mitragotri, S. \& Langer, R.Current status and future potential of transdermal drug delivery. Nature Reviews Drug Discovery, 2004; 3, 115-124.

Rak, J. \& Joanne, L. Y. Oncogenes and tumor angiogenesis: the question of vascular 'supply'and vascular 'demand'. Seminars in cancer biology, 2004. Elsevier, 93-104

Roy, I., Ohulchanskyy, T. Y., Bharali, D. J., Pudavar, H. E., Mistretta, R. A., Kaur, N. \& Prasad, P. N.Optical tracking of organically modified silica nanoparticles as DNA carriers: a nonviral, nanomedicine approach for gene delivery. Proceedings of the National Academy of Sciences of the United States of America, 2005; 102, 279-284.

Sambuy, Y., De Angelis, I., Ranaldi, G., Scarino, M., Stammati, A. \& Zucco, F.The Caco-2 cell line as a model of the intestinal barrier: influence of cell and culture-related factors on Caco-2 cell functional characteristics. Cell biology and toxicology, 2005; 21, 1-26.

Semple, S. C., Chonn, A. \& Cullis, P. R.Interactions of liposomes and lipid-based carrier systems with blood proteins: relation to clearance behaviour in vivo. Advanced drug delivery reviews, 1998; 32, 317.

Senior, J.Fate and behavior of liposomes in vivo: a review of controlling factors. Critical reviews in therapeutic drug carrier systems, 1986; 3, 123-193.

Sheng, Y., Yuan, Y., Liu, C., Tao, X., Shan, X. \& Xu, F.In vitro macrophage uptake and in vivo biodistribution of PLA-PEG nanoparticles loaded with hemoglobin as blood substitutes: effect of PEG content. Journal of Materials Science: Materials in Medicine,2009; 20, 1881-1891.

Smith, S. M., Wunder, M. B., Norris, D. A. \& Shellman, Y. G.A simple protocol for using a LDH-based cytotoxicity assay to assess the effects of death and growth inhibition at the same time. PloS one,2011; 6, e26908.
Suh, J., Choy, K.-L., Lai, S. K., Suk, J. S., Tang, B. C., Prabhu, S. \& Hanes, J.PEGylation of nanoparticles improves their cytoplasmic transport. International journal of nanomedicine, 2007; 2, 735.

Sutradhar, K. B. \& Amin, M. L.Nanotechnology in cancer drug delivery and selective targeting. ISRN Nanotechnology, 2014; 2014.

Verrecchia, T., Spenlehauer, G., Bazile, D., Murry-Brelier, A., Archimbaud, Y. \& Veillard, M.Non-stealth (poly (lactic acid/albumin)) and stealth (poly (lactic acid-polyethylene glycol)) nanoparticles as injectable drug carriers. Journal of Controlled Release, 1995; 36, 49-61.

Win, K. Y. \& Feng, S.-S.Effects of particle size and surface coating on cellular uptake of polymeric nanoparticles for oral delivery of anticancer drugs. Biomaterials, 2005; 26, 2713-2722.

Yamamoto, Y., Nagasaki, Y., Kato, Y., Sugiyama, Y. \& Kataoka, K.Long-circulating poly (ethylene glycol)-poly (d, l-lactide) block copolymer micelles with modulated surface charge. Journal of controlled release, 2001; 77, 27-38.

Yang, Y. \& Rioux, R. M.Highly stereoselective antiMarkovnikov hydrothiolation of alkynes and electron-deficient alkenes by a supported $\mathrm{Cu}-\mathrm{NHC}$ complex. Green Chemistry, 2014; 16, 3916-3925.

Yin, J.-J., Liu, J., Ehrenshaft, M., Roberts, J. E., Fu, P. P., Mason, R. P. \& Zhao, B.Phototoxicity of nano titanium dioxides in HaCaT keratinocytes - generation of reactive oxygen species and cell damage. Toxicology and applied pharmacology,2012; 263, 81-88.

Zhang, L., Gu, F., Chan, J., Wang, A., Langer, R. \& Farokhzad, O.Nanoparticles in medicine: therapeutic applications and developments Clinical pharmacology \& therapeutics, 2008; 83, 761-769.

\section{How to cite this article:}

Almutary AG, Sanderson BJS, Alhalili Z, Ellis AV. Toxicity of thiolated silica nanoparticles modified with sulfobetaine methacrylate for potential use in chemotherapy drug conjugation. $\mathrm{J}$ App Pharm Sci, 2017; 7 (07): 001-009. 